\title{
DEVELOPMENTAL APHASIA OBSERVED IN A DEPARTMENT OF CHILD PSYCHIATRY
}

\author{
BY \\ T. T. S. INGRAM and J. F. REID \\ From the Department of Psychological Medicine, Royal Hospital for Sick Children, Edinburgh, \\ and the Department of Child Life and Health, University of Edinburgh
}

(RECEIVED FOR PUBLICATION DECEMBER 7, 1955)

Recent experience in the Department of Psychological Medicine, Royal Hospital for Sick Children, Edinburgh, has shown that educational difficulties due to developmental aphasia were contributory aetiological factors in a wide variety of behaviour disorders. In the majority of patients the nature of the educational difficulties had not been recognized in time for them to obtain the maximum benefit from remedial teaching. In spite of increasing interest in the condition there still appears to be considerable delay in its diagnosis (Brain, 1955; Methven, 1955; Pearce, 1953; Morley, Court, Miller and Garside, 1955). As a result many children suffer from unnecessarily severe educational retardation and emotional stress. Yet we believe that the histories and findings on examination of the majority of patients constitute a very characteristic clinical syndrome which should be recognized at an early stage. In the present paper we review the findings in 78 children of average intelligence who showed no evidence of cerebral damage.

\section{Terminology}

Specific difficulties in reading and writing have long been recognized as occurring in a proportion of children of average intelligence who show no evidence of cerebral damage. The difficulties were attributed to 'word blindness' by Morgan (1896) and Kerr (1897). When it became realized that many of the children with difficulties in reading and writing also had difficulties in comprehending and using the spoken word the terms 'developmental aphasia' and 'developmental dysphasia' were coined to describe this syndrome (Hinshelwood, 1917; Orton, 1937). Both terms are unfortunate and liable to lead to confusion, for though the majority of patients with developmental aphasia do show expressive or receptive aphasia the difficulties in reading and writing are more consistently present manifestations. The term developmental aphasia has, however, boen retained in this paper for want of another more suitable.

To designate the reading and writing difficulties the terms dyslexia and dysgraphia are employed. By dyslexia is meant specific difficulty in learning to read. This is evidenced quantitatively by retardation in reading attainment relative to the best available estimate of intelligence and qualitatively by resistance to normal methods of teaching and the recurrence of certain characteristic forms of error. The term dysgraphia applies similarly to the operation of writing. The quantitative assessment of dysgraphia is by a test of spelling, but the qualitative assessment covers all aspects of the writing operation, of which motor function is only a part.

\section{Selection of Patients}

Eight hundred and four patients were referred to the Department from January, 1954, to July, 1955, for a wide variety of symptoms, which are shown in Table 1. Among them were 250 in whom educational maladjustment was thought to be important, though only a minority were referred with the complaint of being backward at school. In most of the children educational maladjustment was attributed to intellectual or personality defects or to neurological, visual or auditory abnormalities.

There were, however, 78 children who proved to be of average intelligence on test and who were diagnosed as suffering from developmental aphasia. None of them showed evidence of neural, auditory or cerebral abnormalities to which their symptoms could be attributed.

\section{Sex and Age Distribution}

Sixty-five of the patients were boys, and 13 were girls. The ages varied from 6 to 15 , but more than half were between the ages of 6 and 9 years. 


\section{Reasons for Referral}

The reasons given for the referral of the patients suffering from developmental aphasia, and those of other children sent to the clinic, are shown in Table 1.

TABLE 1

CAUSES OF REFERRAL

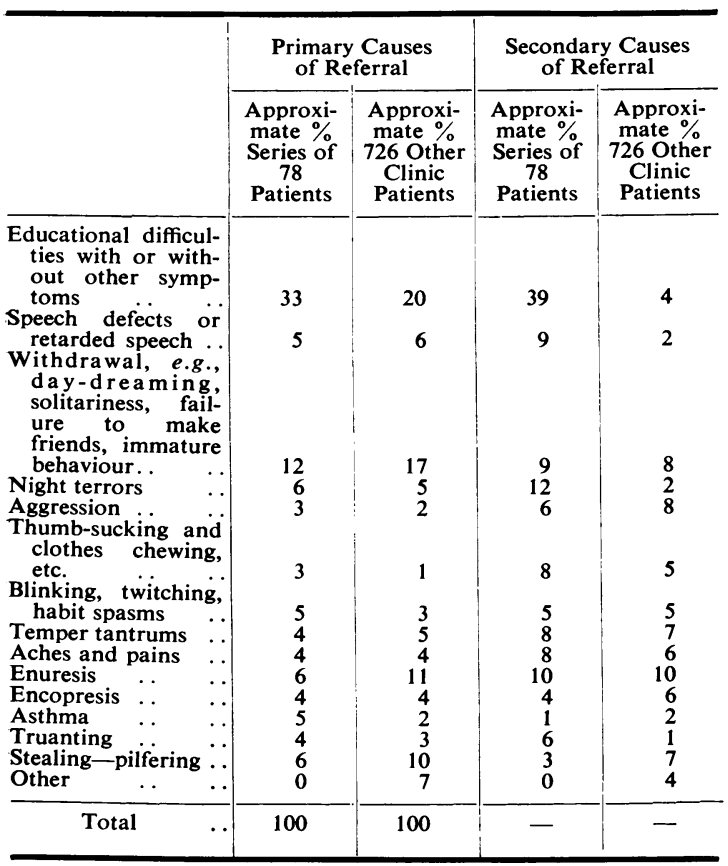

It will be observed that educational difficulties (sometimes specified further as poor progress in learning to read and write) were the premier cause in $33 \%$ of the cases. They were the only symptom in $19 \%$, and associated with others in $14 \%$. In a further $39 \%$ they were a secondary cause, but in as many as $28 \%$ learning difficulties were not mentioned at the time the initial history was taken. Apart from a higher proportion of patients referred on account of learning difficulties, the causes of referral of the group studied were remarkably similar to those of other clinic patients who did not suffer from developmental aphasia.

\section{The Method of Study}

The patients suffering from developmental aphasia were studied in more detail with the aim of defining more accurately the difficulties from which they suffered, and the extent to which hereditary, social and educational circumstances seemed important in producing them.
History Taking. Psychiatric social workers in the Department took detailed histories of the child's physical, mental and social development, and noted any family history suggesting psychiatric disturbances or hereditary physical disorders. Teachers were asked to supplement these histories with details of the child's educational progress. The handedness of the patient's siblings, parents and parents' siblings was determined, usually of necessity by questionnaire. On the basis of their histories the psychiatric social workers attempted to define some of the aetiological factors which might be important in the patient's educational or general behaviour symptoms.

Physical Examination. Every patient was subjected to physical examination, including detailed neurological examination. Audiometry, detailed ophthalmic investigation and electroencephalography were performed when they seemed indicated to exclude the possibility of sensory or cerebral abnormalities.

Tests of 'Handedness'. Handedness was tested rather unscientifically by noting the hand which the child used in each of four performance tests carried out three times. Each patient was asked to turn a door handle, dig with a trowel and catch a ball. Patients using each hand six times or one hand seven times and the other five in the total of 12 sub-tests were arbitrarily classified as ambidextrous (A). Patients using one hand eight or nine times and the other three or four times were classified as being ambidextrous with lateralizing preference $(A / L$ or $A / R)$. If the child used one hand, 10, 11 or 12 times, as the majority of other clinic children did, they were classified as showing definite hand preference ( $R$ or $L)$. 'Footedness' was tested by standing the child at the bottom of a flight of stairs without a banister, and making him climb them three times, and asking him to kick a ball three times. 'Eyedness' was tested by asking the patient to look through a punch hole in a card attached to the desk three times, and to sight a gun or a telescope three times. The eye and foot used for each test was noted. If the patient used each foot or eye for three sub-tests he was classified as showing no preference (A). If he used one eye or foot for four sub-tests he was classified as showing slight preference $(A / R$ or $A / L)$ and if he used the same side in five or six sub-tests he was considered to show marked preference ( $R$ or $L)$.

Speech. In as many cases as possible, interviews with patients were recorded on tape, in order that 
detailed study of their speech could subsequently be made in collaboration with phoneticians. In a few cases it was found impossible to make recordings and speech studies were necessarily incomplete.

Apart from the recording of conversation, receptive and expressive aphasia was also tested by means of a short series of selected questions and commands.

Psychiatric Assessment. Psychiatric interviews with the patients were as frequent as possible and an attempt was made to find out what environmental factors the child felt to be important in causing his difficulties. The final psychiatric assessment was made only after several interviews and in the light of the social history, family background and educational and psychological assessments.

Psychological Assessment. A formal assessment was made of the intellectual capabilities and educational attainment of every patient, excluding 13 who were found to be too anxious or too severely affected for the results to be of value. In 13 of the earlier patients to be studied the Terman Merrill test form $L$ was used in conjunction with the performance scale of the Wechsler intelligence scale for children as a test of intelligence. In the remaining 52 patients complete results are available from testing in the Wechsler scale (hereafter referred to as WISC), and only these will be formally analysed, as it is not legitimate to combine intelligence quotients (I.Q.s) from different tests.

The results of the intelligence test were not taken as exhaustive indications of intellectual capacity. The limitations inherent in them and the degree to which the results are affected by anxiety or specific difficulties are recognized, but the tests were used as the best available estimate of the level which the child might be expected to reach in the basic skills of reading and writing.

Nature OF the Tests. The WISC consists of two scales, or sets of sub-tests, named the verbal and the performance scales. The verbal scale contains five sub-tests:

(1) Information, a test of general knowledge; (2) comprehension, a test of the ability to form and express simple judgments; (3) mental arithmetic, a test of problem solving rather than calculating; (4) similarities, a test of the ability to categorize, and express this in words; (5) vocabulary, a test of the ability to define, or give verbal equivalents for given words.

The performance scale also has five sub-tests:

(1) Picture completion, a test where the child has to find what is missing in a pictured object: per- ception and visualizing power enter into this. (2) Picture arrangement, in which a series of pictures has to be arranged in correct order to tell a story. (3) Block design, a version of Kohs' Blocks, where geometrical designs have to be reproduced to correspond with a given model. (4) Object assembly, a test where cut-up silhouettes of objects bearing some single line drawing have to be put together. Both outline and line drawing are used as clues, and all the joins are straight line cuts. (5) Coding test, a series of geometrical shapes have to be inserted underneath their appropriate numbers (1-9) according to a code given at the top of the page. The version for children under 8 is similar, but does not involve numbers at all.

Educational Assessment. The educational attainment in reading and writing of each child was assessed quantitatively by using the Schonell graded word list as a reading test, and the Schonell graded spelling list $\mathbf{A}$ as a spelling test. From the scores obtained by each child are calculated his reading and spelling ages. From these are derived his reading and spelling quotients by reference to his chronological age. Tests for letter and word reversal were also given and samples were obtained where possible of the child's reading and writing of continuous meaningful material.

\section{Results of Investigation}

Family and Social Backgrounds. The place of all the legitimate children in the family was noted in every case. The distribution by place in the family was not found to differ significantly from that shown by the Registrar-General for Scotland, 1951, for all legitimate live births in Scotland.

The distribution by social class of the father of children with developmental aphasia was compared to that of legitimate live births in counties or cities in Scotland in 1951. There is a significantly higher proportion of patients in social classes I and II, and a smaller proportion in social classes IV and $\mathrm{V}$.

Seventeen of the 78 patients, or $22 \%$, came from broken homes. In 10 cases the parents were divorced or otherwise separated. There was marked parental disharmony, to the point of intermittent separation in the majority, in another 15 cases. Five children were adopted and five lived in institutions or with foster parents. Fifteen of the patients in intact homes had a history of more than one month's separation from the parents in the first two years of life.

One or both parents had received psychiatric treatment in 16 cases, and in a further 13 one or both parents were thought by the psychiatric social 
TABLE 2

HANDEDNESS, EYEDNESS AND FOOTEDNESS OF 78 PATIENTS WITH DEVELOPMENTAL APHASIA

\begin{tabular}{|c|c|c|c|c|c|c|c|c|c|c|c|}
\hline & & \multicolumn{2}{|c|}{$\mathbf{R}$} & \multicolumn{2}{|c|}{$\mathbf{A} / \mathbf{R}$} & \multicolumn{2}{|c|}{$\mathbf{A}$} & \multicolumn{2}{|c|}{$\mathbf{A} / \mathbf{L}$} & \multicolumn{2}{|c|}{$\mathbf{L}$} \\
\hline & & Number & $\begin{array}{l}\text { Approxi- } \\
\text { mate } \%\end{array}$ & Number & $\begin{array}{l}\text { Approxi- } \\
\text { mate } \%\end{array}$ & Number & $\begin{array}{l}\text { Approxi- } \\
\text { mate } \%\end{array}$ & Number & $\begin{array}{l}\text { Approxi- } \\
\text { mate } \%\end{array}$ & Number & $\begin{array}{l}\text { Approxi- } \\
\text { mate } \%\end{array}$ \\
\hline $\begin{array}{l}\text { Handedness } \\
\text { Eyedness } \\
\text { Footedness }\end{array}$ & $\begin{array}{l}\cdots \\
\cdots \\
\cdots\end{array}$ & $\begin{array}{l}13 \\
10 \\
18\end{array}$ & $\begin{array}{l}17 \\
13 \\
23\end{array}$ & $\begin{array}{r}28 \\
7 \\
16\end{array}$ & $\begin{array}{r}35 \\
9 \\
21\end{array}$ & $\begin{array}{r}14 \\
8 \\
15\end{array}$ & $\begin{array}{l}18 \\
10 \\
19\end{array}$ & $\begin{array}{l}14 \\
12 \\
12\end{array}$ & $\begin{array}{l}18 \\
16 \\
16\end{array}$ & $\begin{array}{r}9 \\
41 \\
17\end{array}$ & $\begin{array}{l}12 \\
52 \\
21\end{array}$ \\
\hline
\end{tabular}

$\mathrm{R}=$ right preference; $\mathrm{L}=$ left preference; $\mathrm{A}=$ no preference; $\mathrm{A} / \mathrm{R}$ and $\mathrm{A} / \mathrm{L}=$ slight preference.

worker and psychiatrist in the clinic to be in need of it. A total of 36 of the 149 parents about whom information was available, or $24 \%$, had had or were considered to have need of psychiatric help. Anxiety neurosis was diagnosed in 24 , obsessional neurosis in three, psychosis in five and other disturbances in four. At least 18 of the patients had siblings who had been referred to child guidance or psychiatric clinics.

The parents of 38 children were felt to be unduly concerned about and ambitious for their children's educational attainment. In the majority of these the parents' own anxiety had been projected to the children, whose fear of failure and of letting their parents down was very marked. In at least three cases night terrors could be directly related to the fact that parents had laid undue stress on educational achievement and their children feared that their failure at school might lead to parental rejection. These fears were especially liable to occur in children who had been adopted or who came from broken homes. Typical examples of placing too much stress upon educational achievement may be cited.

The owner of a fish and chip shop who had always had an ambition to be a doctor or a lawyer, and who had quarrelled with his wife and the elder of his two sons, was very ambitious vicariously for the younger, who was of no more than average intelligence. The mother had rejected the boy since birth but the father sent him to an expensive boarding school, which he could ill afford. The son's dyslexia and dysgraphia soon retarded his progress at school. He was referred to the clinic in a state of acute anxiety at the age of 9, very aware of his failure and very fearful that his father's disappointment would lead to rejection by him as well as by the mother.

The only adopted child of brilliant University honours graduates was referred to the clinic at the age of 10 on account of day dreaming, solitariness, a tendency to burst into tears and irrational fears. Investigation showed that he was of no more than average intelligence and was suffering from severe dyslexia and dysgraphia. He had fallen a year behind at school in spite of the fact that he had received several hours of exhausting and often ill-tempered coaching from his parents each night. He felt despised by them and inferior to his contemporaries, and was desperately afraid of parental rejection.
Laterality. The distribution of handedness, eyedness and footedness as determined by the tests described on page 162 is shown in Table 2 . It will be observed that 14 , or approximately $18 \%$ of the patients, were considered to be predominantly ambidextrous showing no obvious hand preference on test. A further 42 showed only slight preference. Nine were left-handed and 13 right-handed. A very high proportion of patients, $52 \%$, were found to be left-eyed and $21 \%$ were left-footed.

As a result of questioning parents about the handedness of other members of the families, it was found that 65 of 108 parents, or $59 \%$, were righthanded, $11 \%$ left-handed and $30 \%$ ambidextrous. Of the 98 siblings about whom information was obtained, $63 \%$ were right-handed, $18 \%$ were lefthanded and $19 \%$ were ambidextrous. Information was obtained about 112 siblings of the parents. Eighty-four per cent. were right-handed, $5 \%$ lefthanded, and $9 \%$ were stated to be ambidextrous. It should be emphasized, however, that these figures were not obtained by direct testing and much reliance cannot be placed upon them.

Twinning. Information was sought as to the number of twins in the families of patients with developmental aphasia. Of the 78 patients, six were known to be twins, including one pair, approximately $8 \%$. Six of the 108 parents about whom details were obtained, were one of twins, and seven of the 112 uncles and aunts of patients were twins, including two pairs. Of the 98 siblings of the patients, four were single survivors of twin births, and two others were a surviving pair.

Speech Defects. A study of the recordings taken during the psychiatric interviews was found to be essential for the detailed study of the abnormalities of speech shown by patients with developmental aphasia. Dysarthria was encountered in only five patients in the sense in which the term is used by Morley, Court and Miller (1954). On the other hand articulatory apraxia was extremely common and occurred in 40 cases. Its commonest manifestations consisted in distortions of speech sounds, 
TABLE 3

AGES AT WHICH 78 PATIENTS WITH DEVELOPMENTAL APHASIA WALKED AND TALKED

\begin{tabular}{|c|c|c|c|c|c|c|}
\hline \multirow{2}{*}{ Age in Months } & \multicolumn{3}{|c|}{ Number of Cases } & \multicolumn{3}{|c|}{ Percentage of Known Cases } \\
\hline & Walking & First Words & Phrases & Walking & First Words & Phrases \\
\hline $\begin{array}{c}9-12 \\
12-15 \\
15-18 \\
18-24 \\
24-30 \\
30-36 \\
36-42 \\
42-48 \\
48+ \\
\text { Unknown }\end{array}$ & $\begin{array}{r}17 \\
36 \\
17 \\
3 \\
0 \\
0 \\
0 \\
0 \\
0 \\
5\end{array}$ & $\begin{array}{r}2 \\
17 \\
12 \\
17 \\
15 \\
5 \\
5 \\
0 \\
0 \\
5 \\
\end{array}$ & $\begin{array}{r}0 \\
0 \\
0 \\
0 \\
14 \\
20 \\
13 \\
12 \\
9 \\
10 \\
\end{array}$ & $\begin{array}{r}23 \\
49 \\
24 \\
4 \\
0 \\
0 \\
0 \\
0 \\
0 \\
-\end{array}$ & $\begin{array}{r}3 \\
23 \\
16 \\
23 \\
19 \\
8 \\
8 \\
0 \\
0 \\
\end{array}$ & $\begin{array}{r}0 \\
0 \\
0 \\
0 \\
20 \\
29 \\
19 \\
18 \\
14 \\
\end{array}$ \\
\hline Total & 78 & 78 & 78 & 100 & 100 & 100 \\
\hline
\end{tabular}

substitutions of one sound for another, irregularities of rhythm, and, in very severe cases only, disturbances in intonation. In children with only slight defects of speech, defective sound production was usually the only abnormality. In more severe cases it was accompanied by disturbances of rhythm which could be very marked. These appeared to be due most commonly to faulty synchronization of abdominal and chest pulses. Abrupt pauses in the middle of phrases were usually due to a dysrhythmic chest pulse and were sometimes accompanied by abrupt glottal closure. Less abrupt pauses were due to expressive aphasia in some cases and in others to unknown causes. Because of the rhythmic disturbance and the tendency for sounds to be slightly distorted the speech tended to sound rather monotonous in some patients though closer study revealed intonation to be normal in the majority. At first hearing the recordings showing marked rhythmic disturbance gave an impression of disordered melody of speech, or dysprosody, as described by Monrad-Krohn (1947). Occasionally when a child with expressive aphasia reversed the order of words in a phrase very anomalous intonation could result. Stutter was evident in seven cases.

In general the severity of speech defects in any single case appeared to be in direct proportion to the severity of the retardation of its development. They were more marked in younger children, and those with expressive or receptive aphasia.

Expressive and Receptive Aphasia. Though the motor milestones of the patients were within normal limits speech development was retarded in more than half the children in the series (Table 3). Fortytwo of the patients, or $58 \%$, said their first words after 18 months, 25 , or $35 \%$, after 2 years, and five, or $8 \%$, were over the age of 3 . The ability to construct phrases was also delayed. Twenty-one, or $32 \%$, could make phrases only after the age of
$3 \frac{1}{2}$ years, and nine, or $14 \%$, were over 4 years. In all the 42 patients whose first words came after 18 months and in a proportion of those who spoke earlier, pronunciation remained grossly defective for a prolonged period and some were still incomprehensible to everyone but the parents at the age of 4 or 5 .

By this time it was evident that the majority of these children had specific difficulties in comprehending speech and in finding words with which to express themselves. Parents often found that the children could talk freely when playing at ease, but that they could not do so when under emotional stress. Fifteen had been noted to blurt out words or phrases which were inappropriate in meaning to what they wanted to say and 12 reversed the order of words in phrases repeatedly without correcting themselves. A commoner complaint occurring in 26 children was typically described as, 'He keeps on forgetting the names of things and then has to describe them by waving his arms about.'

Difficulties in perceiving the significance of speech were suggested by parents complaining that their children were deaf or disobedient, that they ignored what was said to them, or that it took a minute or two before they could answer questions or obey commands.

The most frequent manifestations of aphasia were use of the wrong word (paraphrasia), inability to recall the names of people and objects (nominal aphasia), sudden hesitation during speech because of failure to find words for what the child wanted to express and alterations of the word order which frequently made nonsense of phrases which should have been meaningful. Perseveration was encountered occasionally, and a few severely affected patients were found who were incapable of comprehensible speech except when completely relaxed. Typical examples of the common forms taken by these disorders in practice may be cited. A 9-year-old boy admiring a toy gun said, 'It's a fired one, it isn't, it isn't, it isn't, it's a fired one it 
can .... instead of 'It's a fine one, isn't it? It can fire'. Another child was asked the name of his teacher after an excited conversation about cowboys, and answered, 'Roy Rogers, Sir, Rogers, Sir, Sir, not Rogers ... not sir, Macmillan'. The 'hangover' from preceding conversations was often evident in the content of phrases with which these children had especial difficulty.

Receptive aphasia was manifest in an apparent inability to answer abrupt questions or commands at once unless they were accompanied by gesture. When asked to put out his tongue, or shut his eyes, for example, the child would find it very difficult to comprehend at once what was asked, but would imitate the action of the examiner at once. It was found that unnecessarily detailed descriptions of objects and of actions were rewarded by more rapid and accurate comprehension than were simple statements. Thus a request to, 'Turn the small, round brown handle of the large cream-painted cupboard door and then open it', was much more easily comprehended than a simple request to, 'Open the cupboard'. It was found that under stress and being made to hurry the majority of children with receptive aphasia had difficulty in picking out objects from pictures when these were named to them. It was typical of the children with receptive aphasia that they showed the habit of asking that everything which was said to them be repeated, almost by reflex action. The habit of saying 'What', 'Beg pardon' to everything said by teachers had resulted in strappings for impertinence in a number of cases. The effect of stress appeared to be more marked in accentuating the symptom of receptive aphasia than of expressive aphasia, dyslexia or dysgraphia. When aphasia was present only under exceptional emotional stress or on testing it was classified as mild. When it resulted in intermittent failure to comprehend what was said, or to find appropriate verbal expression, it was classified as moderately severe and when it resulted in persistent difficulty in comprehension and expression it was considered to be severe.

Behaviour and Personality Disturbances. Within six to 12 months of starting school the majority of patients with developmental aphasia had shown symptoms of anxiety, expressed in either behaviour or personality disorder. As has been indicated by the causes of referral, the symptoms shown varied greatly in type and in severity according to the child's personality, and his social and educational environment. Some children reacted aggressively by bullying their fellows, others attempted to compensate for their failure by becoming class clowns and spent their time amusing their fellows and infuriating their teachers rather than attempting work which was becoming progressively more difficult or impossible. One intelligent boy of 14 with severe dysgraphia and dyslexia reacted vigorously to being strapped for spelling mistakes by housebreaking and stealing. But the housebreaking was confined to the school, and the stealing was only from the spelling teacher.

Other children attempted to withdraw from the stressful situation. More than four weeks' absence from school each year on average was reported by 13 cases. In three asthmatics there was a clear relationship in time between attacks and the occurrence of exams or other educational strains at school. Straightforward truanting was present in eight cases. A more subtle character produced vomiting when his work was beyond him, as often as three or four times a week, until his teachers ceased to send him home when he did so.

Children with less robust personalities tended to react to the educational stress less directly. At least two of the five children with nocturnal enuresis had been dry until six months after starting school and were only wet when their schools were in session. Day dreaming, tearfulness, solitariness and temper tantrums were also frequently mentioned in the histories.

As might be expected, the degree of anxiety found bore little relationship to the severity of the dyslexia, dysgraphia or aphasia. Social environment, intelligence level and constitution were more important determining factors.

Psychological and Educational Assessment. The following figures were available for each of the 52 children fully tested: Verbal I.Q., performance I.Q., composite I.Q., reading quotient (R.Q.) and spelling quotient (S.Q.). The 52 children had a mean verbal I.Q. of $101 \cdot 42$, a mean performance I.Q. of $96 \cdot 1$, a mean composite I.Q. of $98 \cdot 15$, a mean R.Q. of 89.0 and a mean S.Q. of $78 \cdot 6$. The difference between verbal and performance I.Q.S was not significant at point 0.05 level. The group as a whole was, however, markedly retarded in reading and more so in writing, the discrepancies being $9 \cdot 15$ points and $19 \cdot 55$ points respectively. Merely to state the results in this way, however, obscures certain important variations in performance, and to demonstrate these the children were subdivided into three groups (Table 4).

Results of Psychological Assessment. In group (a) the verbal scores were higher by more than 8 points than the performance scores, in group (c) the 
TABLE 4

COMPARISON OF READING AND SPELLING OUOTIENTS OF PATIENTS BY RELATIVE SCORES ON PERFORMANCE AND VERBAL SCALES OF THE WECHSLER TEST FOR CHILDREN

\begin{tabular}{|c|c|c|c|c|c|c|c|}
\hline Group & Definition & $\begin{array}{l}\text { Number } \\
\text { I.Q. }\end{array}$ & $\begin{array}{l}\text { Verbal } \\
\text { I.Q. }\end{array}$ & $\begin{array}{l}\text { Performance } \\
\text { I.Q. }\end{array}$ & $\begin{array}{l}\text { Composite } \\
\text { I.Q. }\end{array}$ & $\begin{array}{l}\text { Reading } \\
\text { Quotient }\end{array}$ & $\begin{array}{l}\text { Spelling } \\
\text { Quotient }\end{array}$ \\
\hline $\begin{array}{l}(a) \\
(b) \\
(c)\end{array}$ & $\begin{array}{l}\text { Verbal score better than performance } \\
\text { Verbal and performance equivalent } \\
\text { Performance better than verbal score }\end{array}$ & $\begin{array}{l}23 \\
16 \\
13\end{array}$ & $\begin{array}{r}112 \cdot 3 \\
95 \cdot 6 \\
89 \cdot 3\end{array}$ & $\begin{array}{r}91 \cdot 5 \\
95 \cdot 1 \\
105 \cdot 6\end{array}$ & $\begin{array}{c}101 \cdot 7 \\
95 \cdot 3 \\
97 \cdot 45\end{array}$ & $\begin{array}{r}100 \cdot 3 \\
83 \cdot 5 \\
76 \cdot 4\end{array}$ & $\begin{array}{l}91 \cdot 5 \\
71 \\
65\end{array}$ \\
\hline
\end{tabular}

performance scores were higher by more than 8 points than the verbal and in group $(b)$ the scores were equivalent, not varying by more than 8 points. The reading and spelling quotients (R.Q. and S.Q.) for each group are also shown. The differences in the composite I.Q.s of the three groups are not significant.

A detailed statistical investigation of the sub-test scores on the WISC, studied in relation to severity of retardation and of aphasic symptoms, is at present being undertaken. Results so far obtained appear to indicate that the two sub-tests most difficult for the whole group were similarities and digit symbol, and that the tests differentiating most markedly between groups $(a)$ (verbal better than performance) and (c) (performance better than verbal) were comprehension and vocabulary.

In the course of administering the tests to the patients several characteristic types of confusion were observed repeatedly. In the performance tests, failure to analyse and synthesise patterns, inability to distinguish a pattern from its mirror image and reversal of normal left-to-right serial order were frequent. In the verbal tests confusions similar to those described on page 165 were common. Contrary to what one might expect, examples of these occurred even in records where the final numerical score was relatively high (Table 5).

TABLE 5

SEVERITY OF DYSLEXIA AND DYSGRAPHIA BY RELATIVE SCORES ON VERBAL AND PERFORMANCE TESTING ON THE WECHSLER SCALES

\begin{tabular}{c|c|c|c|c|c|c}
\hline \multirow{2}{*}{ Group } & \multicolumn{3}{|c|}{ Dyslexia } & \multicolumn{3}{|c|}{ Dysgraphia } \\
\cline { 2 - 7 } & Mild & $\begin{array}{c}\text { Moder- } \\
\text { ate }\end{array}$ & Severe & Mild & $\begin{array}{c}\text { Moder- } \\
\text { ate }\end{array}$ & Severe \\
\hline (a) & 16 & 6 & 1 & 7 & 7 & 9 \\
$($ b) & 5 & 5 & 6 & 2 & 5 & 10 \\
$(c)$ & 1 & 4 & 7 & 2 & 3 & 8 \\
\hline
\end{tabular}

The relative severity of dyslexia and dysgraphia, as shown by R.Q. and S.Q., was measured by calculating the difference between the composite I.Q. and the R.Q. and S.Q. in each case. Where the discrepancy was less than 10 points, dyslexia or dysgraphia was considered to be mild, when less than 20 points it was considered moderately severe and when it was 20 points or more it was considered severe. In Tables 5 and 6 are shown the distributions of mild, moderately severe and severe cases of dyslexia and dysgraphia by relative scores on the Wechsler performance and verbal scales, and by the presence or absence of aphasia. There are more severe cases in group $(b)$ than in $(a)$, and most in $(c)$, and there are more among the aphasic than the non-aphasic patients.

TABLE 6

DISTRIBUTION OF APHASIC PATIENTS BY RELATIVE SCORES ON VERBAL AND PERFORMANCE TESTING ON THE WECHSLER SCALES

\begin{tabular}{|c|c|c|c|c|c|}
\hline Group & & (a) & (b) & (c) & Total \\
\hline $\begin{array}{l}\text { Patients without expressive aphasia } \\
\text { Patients with expressive aphasia }\end{array}$ & $\because$. & $\begin{array}{l}10 \\
13\end{array}$ & $\begin{array}{r}3 \\
13\end{array}$ & 12 & $\begin{array}{l}14 \\
38\end{array}$ \\
\hline Total & & 23 & 16 & 13 & 52 \\
\hline
\end{tabular}

Analysis of Errors. The reading errors made by the 52 patients at the time of educational assessment were classified though this was rendered difficult by the fact that similar misreadings may be due to a variety of different mistakes. Most of the reading errors have counterparts in the writing errors which the patients also showed (Table 7).

Though all the various reading errors were encountered in all three groups, $(a),(b)$ and $(c)$, the frequency of each individual type varied. Omission of words and reversal of word order (Error 4) were equally frequent in all groups. Confusion of sounds and symbols, inability to synthesise words from their constituent sounds and failure to recognize the meaning of words when sounded (Errors 6, 7 and 8) were more frequent in groups $(b)$ and $(c)$ than in group $(a)$. On the other hand groups (a) and (b) showed mistakes in 'mirror-image' letters and a tendency to guess at words more frequently (Errors 1 and 5) than did group (c) (Table 8).

Treatment. Treatment had three aspects. From the psychiatric point of view the aim was to diminish the patient's anxiety and restore his lost confidence. The majority of patients responded well once the 
TABLE 7

READING AND WRITING ERRORS IN PATIENTS WITH DEVELOPMENTAL APHASIA

\begin{tabular}{|c|c|}
\hline Reading Errors & Writing Errors \\
\hline $\begin{array}{l}\text { Mistaking one letter for an- } \\
\text { other, especially for its mirror- } \\
\text { image, } b \text { for } d, p \text { for } q \text { or } g \text {, } \\
\text { leading to misreading of words }\end{array}$ & $\begin{array}{l}\text { Writing one letter for another, } \\
\text { especially its mirror-image, } \\
\text { and writing distorted letters }\end{array}$ \\
\hline $\begin{array}{l}\text { 2. Altering the letter order in a } \\
\text { word, or part of a word, often } \\
\text { reading backwards, pot for } \\
\text { top, its for sit }\end{array}$ & $\begin{array}{l}\text { Confusing the order of letters or } \\
\text { groups of letters in a word, } \\
\text { especially tending to reverse } \\
\text { them }\end{array}$ \\
\hline $\begin{array}{l}\text { 3. Repeating the first letter or } \\
\text { group of letters at the end of } \\
\text { the word, gag for gas }\end{array}$ & $\begin{array}{l}\text { Repeating the initial letter or } \\
\text { group of letters at the end of } \\
\text { the word }\end{array}$ \\
\hline $\begin{array}{l}\text { 4. Omitting small words, and } \\
\text { reversing word order when } \\
\text { reading prose }\end{array}$ & $\begin{array}{l}\text { Omitting small words, especially } \\
\text { prepositions }\end{array}$ \\
\hline $\begin{array}{l}\text { 5. Inability to take in the whole } \\
\text { word pattern, and guessing at } \\
\text { the word from the first or last } \\
\text { letters or from the context }\end{array}$ & $\begin{array}{l}\text { Inability to recall visual word } \\
\text { patterns, and tendency to } \\
\text { resort to phonic spelling, i.e., } \\
\text { guessing from analogies of } \\
\text { sounds }\end{array}$ \\
\hline $\begin{array}{l}\text { 6. Confusing the sounds belong- } \\
\text { ing to the written symbols, } \\
\text { e.g., sounding sit as r-u-p. } \\
\text { This may lead to neologisms. }\end{array}$ & $\begin{array}{l}\text { Inability to connect the correctly } \\
\text { analysed sounds of the word } \\
\text { with the appropriate written } \\
\text { symbol }\end{array}$ \\
\hline $\begin{array}{l}\text { 7. Inability to synthesise sound } \\
\text { units into meaningful words, } \\
\text { or to synthesise the sounds } \\
\text { in the correct order, though } \\
\text { the units are correctly sound- } \\
\text { ed. (The child spells out } \\
\text { p-o-t, but cannot produce } \\
\text { the word pot-spells out } \\
\text { s-i-t, and says its.) }\end{array}$ & $\begin{array}{l}\text { Inability to analyse the word } \\
\text { into its constituent sound } \\
\text { units or to retain these in the } \\
\text { correct order }\end{array}$ \\
\hline $\begin{array}{l}\text { 8. Inability to recognize the } \\
\text { meaning of a word or a } \\
\text { phrase, though it may be } \\
\text { correctly sounded and syn- } \\
\text { thesized }\end{array}$ & $\begin{array}{l}\text { Syntactical and other con- } \\
\text { fusions in connected material } \\
\text { indicative of inability to per- } \\
\text { ceive the meaning of what is } \\
\text { to be written }\end{array}$ \\
\hline
\end{tabular}

TABLE 8

PERCENTAGE DISTRIBUTION OF WORD AND LETTER REVERSALS IN 52 FULLY TESTED PATIENTS

\begin{tabular}{c|c|c|c}
\hline Group & $(a)$ & $(b)$ & $(c)$ \\
\hline Letter reversals (errors type 1) & $56 \cdot 5$ & $81 \cdot 2$ & $30 \cdot 0$ \\
Word reversals (errors type 2 and 3) & $26 \cdot 1$ & $31 \cdot 2$ & $38 \cdot 8$ \\
\hline
\end{tabular}

nature of their educational disabilities was explained to them. From the social point of view the aim was to minimize the environmental stresses to which the child was exposed, particularly by modifying the parental attitude to education when this was resulting in too much pressure being exerted on him to be a brilliant scholar. At the same time teachers were encouraged to take a sympathetic attitude to the child's educational handicaps, and a change of school was recommended in severe cases if this was not forthcoming.

From the educational point of view the child was encouraged to appreciate the shapes and patterns of words by using his proprioceptive apparatus.
By teaching writing and reading in close association, proprioceptive and visual appreciation of word and letter shapes was encouraged simultaneously, and reading and writing tended to improve together. The rather experimental teaching methods used will be discussed in more detail in a later paper.

\section{Discussion}

Reversals of letters and of letter order occur in a very large proportion of normal school children for a few weeks when they first begin to read and write. As long ago as 1896, however, persistent difficulty in perceiving the significance of written material was noted to occur in a proportion of otherwise normal children without evidence of cerebral damage (Kerr, 1897; Morgan, 1896). To these difficulties the descriptive term 'word blindness' was applied. Initially, difficulties with reading appear to have been regarded as the sole manifestation of the disorder, and only gradually have other clinical features come to be added to comprise the syndrome of developmental aphasia (Hinshelwood, 1917; Orton, 1937; Ombredane, 1944; Hallgren, 1950; Morley et al., 1955). It is now generally recognized that specific dyslexia is almost always associated with specific dysgraphia, and the frequency with which receptive aphasia (congenital auditory imperception) and expressive aphasia (verbal dysphasia) occur is also being realized (Brain, 1945, 1955).

The Aetiology of Developmental Aphasia. In a proportion of patients with dyslexia, dysgraphia and aphasia it is by no means easy to determine whether the symptoms are the result of cerebral damage or malformation, or due to developmental aphasia (Dunsdon, 1952). In the present series great care was taken to exclude cases with cerebral damage by detailed examination and investigation. None had a history suggestive of cerebral birth injury and no significant neurological abnormalities were apparent.

There is, in fact, much evidence that there is a hereditary element in the aetiology of developmental aphasia. As a result of a detailed study of dyslexic patients and their families, Hallgren obtained evidence suggesting that dyslexia was due to an autosomal Mendelian dominant gene. If this is so the penetrance of the gene must be extremely variable and probably depends upon a number of complex environmental factors, for the severity of the symptoms shown even by identical twins varies very greatly.

Though the majority of published series of dyslexic patients report a high preponderance of males over 
females, in about the ratio of 5 to 1 , the explanation for this is obscure (Wallin, 1921, 1949). Our male to female ratio of 5 to 1 in the series compares with that of 5.5 to $4 \cdot 5$ for all other clinic referrals. Hallgren states that he could find no evidence of sex linkage in the inheritance of dyslexia. In part the difference may be due to selection of cases. In series consisting of referrals to child guidance clinics the male preponderance is greater than in series derived from field studies. It seems possible that the patriarchal societies of both Sweden and Scotland place greater emphasis on the need for educational success in the male than in the female and that this results in readier referral of the male who is having learning difficulties.

The sex difference may be related to the fact that there are more ambidextrous males than females in the population and that aphasic symptoms occur more frequently in children with slight tendencies to hand and eye preference than those with marked unilateral dominance (Granjon-Galifret and Ajuriaguerra, 1951).

It has been suggested that dyslexia and dysgraphia tend to occur more frequently in children with a family history of twinning, and in twins than in those who are single births (Macmeeken, 1939). In the present series it was found that there was a high proportion of twins amongst the patients, their siblings, parents and their uncles and aunts compared to that expected on the basis of the estimate that $1.3 \%$ of all live births are twin. The place in the family of patients with developmental aphasia is not significantly different from that of all live births in the general population in Scotland (Registrar General for Scotland, 1951). This is in accordance with the findings of Hallgren in Stockholm.

That environmental factors play an important factor in exacerbating aphasic symptoms is indicated by the way in which many of the patients showed dramatic improvement in school work when home and school conditions were ameliorated. The high proportion of patients in social classes I and II is probably due in part to the greater stress laid by parents and schools on the need for educational success than in the lower social classes. The frequency with which a history of broken homes, parental disharmony, parental over-anxiety and prolonged periods of separation from parents in the early years of life was found has been described.

All these factors might be regarded as environmental causes of anxiety and insecurity in the child and thus as contributory factors in his lack of confidence and poor educational progress.
Handedness of Patients with Congenital Aphasia and of their Families. The handedness, eyedness, footedness and 'visual-fieldedness' of children suffering from dyslexia and dysgraphia have attracted much attention, but there is still great controversy about the significance of finding evidence of sinistrality, crossed laterality between hand and eye and ambidexterity.

In a series of elementary school children in Edinburgh it was found that dyslexia was commoner amongst those who were left-eyed than those who were right-eyed (Macmeeken, 1939). The possible aetiological importance in dyslexia of sinistrality, crossed laterality and ambidexterity has been stressed by Orton (1937) and by Schonell (1948). It has been suggested, however, that the laterality of visual-fieldedness is of greater importance in determining the side of cerebral dominance than is the laterality of eyedness. Unfortunately the apparatus used for testing fieldedness is impractical for routine clinical use and the method is not without theoretical objections (McFie, 1952).

No significant relationship between the incidence of left handedness, left eyedness or cross laterality and the occurrence of congenital dyslexia was found in a controlled study by Hallgren (1950). Exception must be taken, however, to his tendency to classify patients as either right or left handed rather than as ambidextrous as was done by Granjon-Galifret and Ajuriaguerra (1951). The latter authors attempted to define handedness and eyedness in terms of the strength of the lateralizing propensities found on test. They reported that there was a higher incidence of ambidexterity, absence of strong hand preference, in a series of dyslexic patients than in a series of controls. There was no significant difference in the incidence of left handedness between the two groups.

It will be seen from Table 2 that in our series 56 of the 78 patients, or approximately $71 \%$, failed to show marked preference for one hand, and $56 \%$ showed little preference for one foot rather than the other. Thirty-five per cent. of patients were considered to show marked laterality in eyedness though as many as $52 \%$ were left eyed on test. When handedness is defined in terms of absence of marked laterality it is obviously of little value to determine the numbers of patients showing crossed laterality of dominant hand and eye. Our findings are very similar to those of Granjon-Galifret and Ajuriaguerra in their group of dyslexic patients allowing for difference in classification and our cruder techniques of determining laterality.

A number of authors have reported that there is a high incidence of left-handedness and ambi- 
dexterity amongst relatives of children with dyslexia (Orton, 1937, 1943). That this is so has been denied by Hallgren (1950). In an unselected series of 4,449 elementary school children in Edinburgh under the age of 9 years who were examined by questionnaire, it was found that $8.65 \%$ were lefthanded with a significantly higher number of boys than girls (Chisholm, 1954). This percentage is lower than that for patients $(11 \%)$, their siblings $(18 \%)$ and their parents $(11 \%)$ in our series of cases. But these differences are not statistically significant. Series of normal children with which to compare the incidence of ambidexterity in our patients are not available.

Description of the Symptoms. The difficulties in learning to read and write have been fully described by a number of authors whose work is summarized by Hallgren (1950) and Brain (1955). They are very similar to those encountered in our patients. We have found no author, however, who sufficiently stresses how often retarded speech development, expressive and receptive aphasia and speech defects are found among patients with dyslexia and dysgraphia. The association of these disorders is noted by a number of workers, but there still appears to be a tendency to consider dyslexia and dysgraphia on the one hand, and expressive and receptive aphasia on the other, as rather distinct disorders (Orton, 1937; Brain, 1955). Since our series is not dissimilar in other respects to a number of others which have been published our higher incidence of aphasia is unlikely to be due to differences in sampling.

The speech defects which were noted in our cases were very similar to those described by Morley et al. (1955). Unfortunately most of their patients were under school age and the incidence of dysgraphia and dyslexia amongst them could not be determined. It seems likely, however, that these disorders must occur relatively commonly amongst similar patients referred to clinics of speech therapy.

A number of authors have stressed the importance of emotional factors in determining educational difficulties in general and reading difficulties in particular (Burt, 1947; Gann, 1945). On the other hand the complex relationship between anxiety provoked by school difficulties and dyslexia and dysgraphia exacerbated by anxiety has not received the attention it deserves, though emphasized by Orton (1937) and Hallgren (1950). The latter author found that $58 \%$ of a series of dyslexic patients ascertained in school had one or more nervous symptoms compared with $33 \%$ in a control group. The symptoms shown by our cases were not dissimilar from those of other referrals for child guidance.
Four common types of emotional disturbance secondary to specific dyslexia-the "couldn't care less', the paranoid reaction to the teacher, marked feelings of inferiority and a tendency to emotional blocking-were described by McCreedy (1926). We would only comment that the "couldn't care less' attitude is very often a shallow veneer on the surface of deep anxiety, that in Scotland, where the strap is used too freely to encourage learning, the paranoia is usually justified, that the feelings of inferiority are often associated with fears of rejection and that it was often extremely difficult to determine to what extent 'blocking' was emotional and how much of it was due to aphasia.

Nature of the Disability in Congenital Dyslexia and Dysgraphia. Many efforts have been made to specify more precisely the nature of the difficulties in reading and writing suffered by dyslexic and dysgraphic children. Unfortunately these have been expressed in a variety of incomprehensible and mutually incompatible terms which make appreciation of their merits very difficult, as has been noted by Schilder (1944) and Brain (1955). They vary from interpretations of the symptoms in terms of defective Gestalt and theories of abnormal functional cerebral symmetry to logical positivist reflections upon individual variations as to what is understood by single words. The relevant theories and literature have recently been reviewed by Brain (1955).

A study of the test results in Table 5, in which the degrees of dyslexia and dysgraphia for the three groups are shown, yields the following observations:

(1) The groups increase in severity of retardation relative to composite I.Q., the increase being steeper in writing than in reading.

(2) The increase in severity of both dyslexia and dysgraphia is directly proportional to the verbal I.Q., the R.Q. being approximately 12 points below the verbal I.Q. in each group, and the S.Q. being from 21 to 24 points below.

(3) In each group dysgraphia is more severe than dyslexia.

(4) Group (c), which has the highest mean performance I.Q., is the most severely retarded.

As indicated above in intelligence testing, group (a) showed predominantly spatial difficulties, group (b) showed spatial and aphasic verbal difficulties in equal proportions, while group (c) showed predominantly aphasic difficulties. It was also noted that there seemed to be characteristic errors associated with these groups, certain kinds being more typical of groups $(a)$ and $(b)$, and certain others of groups $(b)$ and $(c)$.

Group $(a)$, in which the proportion of aphasic 
patients was small, was relatively free of errors involving the sound of individual letter symbols, the synthesis of sounds into words and the comprehension of words or phrases when sounded and synthesized (Errors 6,7 and 8). Their mistakes were chiefly in perceiving or recalling shape and position (Errors 1, 4 and 5) and formed a parallel to their failures in intellectual testing. Group (b) exhibited similar errors, but in addition showed many errors in common with group (c). Both these groups, but (c) especially, contained patients with receptive and expressive aphasia, and their errors consisted mainly of failures in sound identification, synthesis, and association of meaning and symbol (Errors 6, 7 and 8). These difficulties were correlated with reversals and confusions of whole words (Errors 2 and 3) rather than of individual letters.

On the basis of these findings, a tentative definition of these forms of difficulty suggests itself. As has been emphasized, the difficulties occur less frequently in isolation than in association in affected children, though their relative severity varies.

First there is difficulty in dealing with shapes, recognizing them, reproducing them, and relating them to another, especially in the horizontal plane. This spatial or 'lateralizing' disability is manifest as relatively poor ability in performance tests, with the confusions mentioned on pages 162 and 164 . In reading there is faulty word recognition or recall, especially of small words, and confusion of mirror image letters. The importance of errors of this type has been emphasized by Orton (1937) and Pearce (1953).

Secondly, either with or without spatial disabilities there may be difficulty in relating the sound or phonic unit to its written equivalent in synthesising sounds into words and in analysing words into sounds. This difficulty is found especially frequently in patients with expressive or receptive aphasia. It is manifest in reading and writing by confusion of vowel sounds, reversal of words and parts of words and inability to construct meaningful words even when the individual written components have been correctly sounded (Schilder, 1944).

Thirdly, there is difficulty in appreciating the meaning of either spoken or written words, and especial difficulty with relational words, for instance conjunctions, prepositions or auxiliary verbs, whose meaning in isolation is much more elusive than that of most verbs and nouns. These words were often omitted, reversed or confused with one another. The difficulty in perceiving words to be meaningful appeared to be closely related to the inability to deal with tests of classifying and of finding verbal equivalents for given words. It was most marked in patients with expressive and receptive aphasia and even when it was not associated with marked spatial difficulties, as in group (c), its presence appeared to preclude easy learning of reading or writing. In particular, facility in relating written word shapes directly to meaning failed to develop. The nature of this difficulty in perceiving the meaning of words is very difficult to define more precisely without becoming involved in philosophical speculation, but it is reminiscent of the defect of comprehension noted by Head (1926) in patients with 'semantic aphasia'.

The observed difference in severity between the groups defined in terms of their scores on verbal and performance tests is in accordance with the findings of Schonell (1948). This author stresses that the spoken word is the symbol to which meaning is first attached and that written symbols acquire meaning only through their equivalence to the spoken. It would therefore be expected that difficulties with the basic symbols of communication (as in patients with expressive or receptive aphasia) would lead to reading problems of a more fundamental kind than would difficulties with visual symbols only. The inevitable association of reading and writing difficulties with acquired expressive and receptive aphasia was similarly explained by Head (1926).

The severity of the reading and writing difficulties in our patients appeared to be paralleled by their relative failure on tests of the ability to define and categorize, and that this latter operation seemed to be the most difficult verbal one for all three groups. This suggests that these failures may be closely related to the underlying conceptual difficulty in developmental aphasia. But clearly much work is required before it will be possible to define the nature of this conceptual disability more accurately and determine its relationship to the spatial difficulties on the one hand and the phonic and semantic difficulties on the other which are such prominent features of the condition. In the present state of knowledge it seems to us that there has already been more than enough speculation on the possibility that variations in the laterality of cerebral function may be responsible for developmental aphasia.

\section{Summary}

A description is presented of an investigation of 78 children of average intelligence, referred to a department of child psychiatry, who were found to have specific dyslexia and dysgraphia due to developmental aphasia.

The types of reading and writing errors encountered are described and classified. The frequency 
with which retarded speech development, expressive and receptive aphasia and speech defects are found is emphasized. A high proportion of the patients, their siblings and their parents were found to be ambidextrous. The behaviour disorders shown by the patients are described and the aetiological importance of educational difficulties in producing them is discussed.

The writing and reading difficulties tended to be more severe in patients with receptive or expressive aphasia. Three types of difficulty in reading and writing could be defined by relating the types of errors found to the failure of the patients on various sub-tests of the Wechsler verbal and performance scales. They were present in association in different degrees of severity in different patients. The difficulties appeared to be due to:

(1) Inability to perceive the relationship of shapes and letters in space and in reproducing them correctly; (2) failure to relate phonic and written symbols correctly to each other; (3) failure to perceive the meaning or significance of the written or spoken word. The severity of the learning difficulties appeared to be most closely related to the third factor, and it is suggested that this may be a pointer to the direction which further investigation of the underlying conceptual difficulties in developmental aphasia should take.

We are grateful to the psychiatric social workers in the Department of Psychological Medicine for their detailed histories of the patients, and for their interest and cooperation in the investigation.

We wish to thank Dr. Margaret Methven for permis- sion to make the investigation and are grateful to her, to Professor James Drever and Professor R. W. B. Ellis for their interest, constructive criticism, and help in the preparation of this paper.

We are grateful to Mr. David Abercrombie, Department of Phonetics, University of Edinburgh, for his expert study of our tape recordings.

\section{REFERENCES}

Brain, W. R. (1945). Lancet, 2, 837

(1955). In Neurology, by S. A. K. Wilson, 2nd ed., vol. 3 , ch. 83. London.

Burt, C. (1947). Mental and Scholastic Tests, 2nd ed. London.

Chisholm, F. B. (1954). Handedness of School Children in Scotland with Special Reference to Writing.' Unpublished typescript.

Dunsdon, M. I. (1952). The Educability of Cerebral Palsied Children. London.

Gann, E. (1945). Reading Difficulty and Personality Organization. New York.

Granjon-Galifret, N. and Ajuriaguerra, J. (1951). Encéphale, 40, 385 .

Hallgren, B. (1950). Acta psychiat. neurol. scand., Suppl. 65.

Head, H. (1926). Aphasia and Kindred Disorders of Speech. Cambridge.

Hinshelwood, J. (1917). Congenital Word-Blindness. London.

Kerr, J. (1897). J. rov. statist. Soc., 60, 613

Macmeeken, M. (1939). Ocular Dominance in Relation to Developmental Aphasia.' London.

McCready, E. B. (1926). Amer. J. Pyschiat., 6, 267.

McFie, J. (1952). J. Neurol. Neurosurg. Psychiat., 15, 194.

Methven, M. M. (1955). Practitioner, 174, 476.

Monrad-Krohn, G. H. (1947). Acta psychiat. neurol. scand. Suppl. 46, 204.

Morgan, W. P. (1896). Brit. med. J., 2, 1378.

Morky, M., Court, D. and Miller, H. (1954). Ibid., 1, 8.

,- 1, and Garside, R. F. (1955). Ibid., 2, 463

Ombredane, A. (1944). Études de psychologie médicale. Rio de Janeiro.

Orton, S. T. (1937). 'Reading, Writing and Speech Problems in Children.' New York

- (1943). Arch. Ophthal. (Chicago), 30, 707.

Pearce, R. A. H. (1953). Archives of Disease in Childhood, $28,247$.

Registrar General for Scotiand (1951). Annual Reports. H.M. Stationery Office.

Schilder, P. (1944). J. Genet. Psychol., 65, 67.

Schonell, F. J. (1948). Backwardness in the Basic Subjects, 4th ed. London and Edinburgh.

Wallin. J. E. W. (1921). Lancet, 1, 890.

Wallin, (1949). "Children with Mental and Physical Handicaps." New York. 